\title{
Primary Large B Cell Lymphoma of the Cervix: A Case Report and review of literature
}

\author{
Soheila Aminimoghaddam ${ }^{1}$, Elnaz Salarifar ${ }^{1}$, and Somayyeh Noei Teymoordash ${ }^{1}$ \\ ${ }^{1}$ IUMS
}

October 14, 2021

\begin{abstract}
Abstract The primary diffuse large B cell lymphoma (DLBCL) of the uterine cervix is extremely rare. In the present study, we described two cases of DLBCL of the uterine cervix in reproductive-aged women complaining of postcoital bleeding, recurrent vaginal discharge, and abnormal uterine bleeding.
\end{abstract}

\section{Introduction}

Primary lymphomas of the female genital tract are quite rare entity, accounting for $0.2 \%-1.1 \%$ of all cases of extra-nodal lymphoma (1). Extra-nodal non-Hodgkin lymphoma (NHL) affects the gastrointestinal tract and central nervous system, however, it is additionally sometimes recognized in the breast, thyroid, prostate, bones, and female genitalia tract (2). Patients usually present with abnormal vaginal bleeding, and clinically, the cervix is expanded by a subepithelial mass without ulceration. Given the lymphoma is unexpected at the cervix, it might be not diagnosed by a pathologist in Papanicolaou (Pap) smear and also, might be mistaken with other types of malignant neoplasms or inflammatory processes. (3). Due to the rarity of this diagnosis, management approaches are anecdotal and there is no clear consensus. However, general guidelines can be suggested.

Here we reported two cases of diffuse large B cell lymphoma (DLBCL) of the uterine cervix. The importance of presenting to these patients includes the following: (1) cervical lymphoma is a rare entity, (2) complaints of postcoital bleeding are important, and should be taken seriously, (3) abnormal appearance of the cervix should be evaluated with colposcopy by a gynecology oncologist or experienced gynecologist.

\section{Case Presentation}

Case 1

A 38-year-old woman gravida 1, para 1, presented to the Department of Obstetrics and Gynecology in Firoozgar medical center in Tehran, Iran on October, 2018 with compliant of postcoital bleeding for the past 6 months. Her medical history and family history of cancer was completely uneventful. She was not immunologically compromised nor was taking any immune-modulating medication. Physical examination revealed no abnormal finding on systemic examination. No palpable cervical, axillary or inguinal lymphadenopathy was found. Pelvic examination revealed abnormal bulky cervix with no parametrial involvement in rectovaginal examination.

Punch biopsy of the cervical mass was performed. Diffuse infiltration of the exocervical and endocervical stroma by monomorphic population of malignant lymphoid cells with intermediate to large, round to ovoid and irregular nuclei surrounded by scanty neoplasm was observed. Neutrophilic infiltration and large foci of necrosis were also noted. In immunohistochemical study, the neoplastic cells were positive for B cell markers and negative for pancytokeratin. A diagnosis of diffuse large B cell NHL was made [Fig.1]. 
Chest computed tomography (CT) scan, bone marrow examination, serum tumor markers, lactate dehydrogenase were unremarkable. Pelvic magnetic resonance imaging (MRI) showed infiltrative mass of the cervix measuring about $40 \mathrm{~mm}$ with mild enhancement and restricted diffusion without local invasion to the rectum or bladder. Contrast-enhanced axial abdominopelvic CT revealed cervical enlargement and some small lymph node with $\mathrm{SAD}=6 \mathrm{~mm}$ in internal iliac vessels [Fig. 2].

Staging was compatible with stage I (E) DLBCL of the cervix. The patient was discussed in a multidisciplinary session and she was candidate for systemic R-CHOP (Rituximab, Cyclophosphamide, Adriamycin, Vincristine, Prednisolone) chemotherapy. Chest and Abdominopelvic PET scans were performed after completion of chemotherapy, which indicated complete remission [Fig. 3].

\section{Case 2}

A 30-year-old woman gravida 1, para 1, with complaint of a one-year history of postcoital bleeding, abnormal uterine bleeding and recurrent vaginal discharge presented to the Department of Obstetrics and Gynecology in Firoozgar Hospital in Tehran, Iran in august, 2019. Her past medical history and family history for cancer was negative. High-risk subtypes Human Papillomavirus (HPV) testing was positive for HPV-16, although cervical cytology was negative for intraepithelial lesion or malignancy. No palpable cervical, axillary or inguinal lymphadenopathy was found. Pelvic examination revealed a fixed hypertrophic cervix with abnormal consistency. There was parametrial involvement in rectovaginal examination.

Endometrial biopsy, endocervical curettage (ECC), and colposcopy were performed. Colposcopic evaluation revealed abnormal vessels. Pathology examination showed low grade cervical intraepithelial neoplasia (CIN I). A month later, punch biopsy of the cervix was repeated due to the more severe and persistent vaginal discharge. A diagnosis of diffuse large B cell NHL was reported [Fig.4]. Transvaginal sonography demonstrated a heterogeneous and infiltrative mass of the cervix measuring about $40 * 54 \mathrm{~mm}$ with increased vessels flow. Contrast-enhanced axial CT of abdominopelvic showed a $63^{*} 74 \mathrm{~mm}$ hypodense solid mass in cervix with heterogeneous enhancement and some pathologic lymph node in bilateral iliac vessels with SAD of $8 \mathrm{~mm}$ [Fig. 5]. Pelvic MRI revealed a $40 \mathrm{~mm}$ infiltrative circumferential mass of the cervix with vaginal wall involvement. The mass had restricted diffusion in Diffusion-weighted imaging (4) and heterogenous post gadolinium enhancement. The liver, spleen, and para-aorta were normal. Diagnosis of large B cell CD 20 positive lymphoma of the cervix was confirmed in a review by an expert pathologist. The stage of the tumor considered as II (E) using the Ann Arbor system. After discussion at tumor board, patient underwent R-CHOP based chemotherapy. During 1-years follow-up, there was no evidence of clinical recurrence and she delivered a healthy term baby. She was in a good condition during postpartum period.

\section{Discussion}

In this case report, we described two women presented to the Gyneco-oncology clinic with symptoms of postcoital bleeding and negative cervical cytology ultimately diagnosed as diffuse large B-cell lymphomas (DLBCL). Primary female genital lymphomas are extremely rare neoplasms that make up $0.2 \%$ to $1.1 \%$ of all extra-nodal cases (2). The age range at the time of the diagnosis is generally wide (20 to 80 years) with an average age of 40 to 59 years old. (5). In the literature review, diffuse large B-cell lymphomas (DLBCL) were the most frequent histologic type reported (6). Others included follicular lymphoma, Burkitt lymphoma, and Mucosal-associated lymphoid tissue lymphoma (7). Table 1 depicts some cases of DLBCL of the uterine cervix reported in the literature.

Study by Nasioudis et al revealed most cases are diagnosed at an early stage (I or II) according to Ann Arbor classification. Unlike other gynecological malignancies, primary lymphomas of the genital tract have a good prognosis, even when diagnosed at an advanced stage (7).

Due to the fact that lymphoma infiltrate the cervical stroma and the squamous and glandular epithelial lining is preserved in the early stages, the cervical cytology is non-diagnostic in most cases (3). In a study conducted by Dursun et al . abnormal cervical cytology was observed in $41 \%$ of women affected with primary cervical lymphoma (8). Histologic diagnosis might be difficult which occasionally necessitates histological review 
and immunohistochemical study by an experienced pathologist. It is important to distinguish malignant lymphoma from undifferentiated cervical carcinoma, sarcoma, small-cell neuroendocrine carcinoma because cervical lymphoma can be successfully treated in spite of locally advanced disease [9]. The best standard treatment option for primary malignant lymphoma of the uterine cervix should be assigned to the individuals; however, treatment approaches include surgery, chemotherapy, or radiotherapy. Clearly, treatment with systemic therapy using combination chemotherapy regimens is indicated in the majority of cases $(6,7,9)$. The recommended regimen is $\mathrm{R}-\mathrm{CHOP}$, which is rituximab, a monoclonal antibody to CD20, cyclophosphamide, doxorubicin, vincristine, and prednisolone.

There is no evidence that radical gynecologic surgery is advantageous and should be avoided (10). Surgery has been used as an adjunct to chemotherapy, either before or after chemotherapy, especially in patients with stage I or II disease. Radiation therapy following chemotherapy should be considered, particularly for bulky tumors $(>10 \mathrm{~cm})$ and residual disease which does not completely respond to chemotherapy $(6,11)$.

Young patients who wish to preserve fertility can be counseled about the possibility of conization followed by chemotherapy and close follow-up. Conception has been reported in patients treated successfully, although the outcome of these pregnancies is unclear due to their overall rarity (12).

Masashi Ohe et al in 2012 reported a 71_year_old woman with DLBCL lymphoma which was treated with clarithromycin and prednisolone along with radiotherapy and complete remission was achieved after 6 months (13).

Maureen et al in 2018 reported a 55 _year_old woman with compliant of AUB and diagnosis of DLBCL. After multi-agent chemotherapy with 3 cycles of R-CHOP, remission was achieved (14). Mousavi Seresht et al in 2018 reported a 31_year_old woman with AUB and diagnosis of non-Hodgkin's B cell lymphoma of the cervix. She received chemotherapy of CHOP regimen and on the 14th month of follow-up, she was disease-free with no signs of a recurrence (15).

\section{Conclusion}

Patients with symptoms including vaginal discharge, postcoital bleeding and abnormal uterine bleeding initially seek the gynecologists. It might be not diagnosed by a pathologist in Papanicolaou (Pap) smear and also, might be mistaken with other types of malignant neoplasms or inflammatory processes. To prevent delays in diagnosis, it is important for gynecologists and pathologists to identify these cases as early as possible and take the appropriate management to improve therapy.

\section{Acknowledgements}

The authors would like to thank the Firoozgar clinical Research development Center, Firoozgar Medical Center, Iran University of Medical Sciences, Tehran, Iran.

\section{Conflict of interest}

The authors have no conflicts of interest to declare.

\section{Funding}

Non

\section{Ethical approval}

Informed consent was provided for the purpose of publication of images and other clinical information in this case report. In addition, no identifying personal details are included in this manuscript.

\section{Contributors}

$\mathrm{S}$ A was the surgeon involved in the case and contributed to writing of the article. E S contributed to writing the first draft. S NT contributed to writing the final draft and revision of the article.

\section{References}


1. Lagoo AS, Robboy SJ. Lymphoma of the female genital tract: current status. Int J Gynecol Pathol. $2006 ; 25(1): 1-21$.

2. Wang J, Zeng L, Chen S, Wu Q, Ma L, Wu S, et al. Lymphoma of the female genital tract: a clinicopatholngical analysis of 25 cases. Am J Transl Res. 2019;11(9):5800-11.

3. Calli AO, Rezanko T, Yigit S, Payzin B. Lymphoma of the cervix: A diagnostic pitfall on cervicovaginal smear. J Cytol. 2012;29(3):213-5.

4. Lynch HT, Casey MJ, Snyder CL, Bewtra C, Lynch JF, Butts M, et al. Hereditary ovarian carcinoma: heterogeneity, molecular genetics, pathology, and management. Molecular oncology. 2009;3(2):97-137.

5. Yalta T, Taştekin E, Puyan FÖ, Usta U, Azatçam M, Altaner S. Non-Hodgkin's lymphoma: A rare diagnosis on cervicovaginal cytology. J Cytol. 2012;29(2):142-3.

6. De-La-Noval B DGA, Hernández, I Z, García J D-S, Tejeda D. Successful Treatment of a Primary Cervical Diffuse Large B-cell Lymphoma with Rituximab-CHOP Immunochemotherapy. Int J Blood Res Disord.3(1):024.

7. Nasioudis D, Kampaktsis PN, Frey M, Witkin SS, Holcomb K. Primary lymphoma of the female genital tract: An analysis of 697 cases. Gynecol Oncol. 2017;145(2):305-9.

8. Dursun P, Gultekin M, Bozdag G, Usubutun A, Uner A, Celik NY, et al. Primary cervical lymphoma: report of two cases and review of the literature. Gynecol Oncol. 2005;98(3):484-9.

9. Garavaglia E, Taccagni G, Montoli S, Panacci N, Ponzoni M, Frigerio L, et al. Primary stage I-IIE nonHodgkin's lymphoma of uterine cervix and upper vagina: evidence for a conservative approach in a study on three patients. Gynecol Oncol. 2005;97(1):214-8.

10. Mandato VD, Palermo R, Falbo A, Capodanno I, Capodanno F, Gelli MC, et al. Primary diffuse large B-cell lymphoma of the uterus: case report and review. Anticancer Res. 2014;34(8):4377-90.

11. Heredia F, Bravo M, Pierotic M, Majlis A, Carmona L. Neoadjuvant combined chemotherapy followed by external whole pelvic irradiation in two cases of primary extranodal non-Hodgkin's lymphoma of the uterine cervix. Gynecol Oncol. 2005;97(1):285-7.

12. Sandvei R, Lote K, Svendsen E, Thunold S. Successful pregnancy following treatment of primary malignant lymphoma of the uterine cervix. Gynecol Oncol. 1990;38(1):128-31.

13. Ohe M, Hashino S, Hattori A. Successful treatment of diffuse large B-cell lymphoma with clarithromycin and prednisolone. Korean J Hematol. 2012;47(4):293-7.

14. Roberts ME, Cottrill HM. A case of primary cervical lymphoma in a patient with abnormal uterine bleeding. Gynecol Oncol Rep. 2018;26:105-7.

15. Mousavi Seresht L, Yousefi Z, Davachi B, Jafarian AH, Mottaghi M, Azimi H, et al. Primary Malignant Lymphoma of Cervix: A Case Report. Journal of Midwifery and Reproductive Health. 2019;7(4):1981-5.

16. González-Mariño MA. Primary lymphoma of the uterine cervix: Case Report. Case reports. 2021;7(1):1521.

17. Menon PD, Tariq H, Forker C, Nazarullah A. Diagnosis of uterine lymphoma on cervical pap smear: Case report and review of literature. Human Pathology: Case Reports. 2021;23:200466.

18. Gengrong Liu ZS, Liefen Yin, Zhe Zhang, Lingmei Yin, Ke Wang, Huan Yang, Jin Yao. An elderly patient with primary cervical CD5-positive diffuse large B-cell lymphoma: a case report and review of the literature. European Journal of Gynaecological Oncology. 2020;41(4):500-3.

19. Del M, Angeles MA, Syrykh C, Martínez-Gómez C, Martínez A, Ferron G, et al. Primary B-Cell lymphoma of the uterine cervix presenting with right ureter hydronephrosis: A case report. Gynecol Oncol Rep. 


\section{0;34:100639.}

20. Murata H, Nakamura H, Ohta Y, Kitamura M, Nakastuka S, Ishikawa J, et al. Two cases of spindle cell variant diffuse large B-cell lymphoma of the uterine cervix. Gynecol Oncol Rep. 2020;33:100611.

Table 1 : Some cases of diffuse large B-cell lymphoma of the cervix in the literature review

\section{Authors}

González-Mariño, 2021(16)

P. D. Menon, 2021 (17)

Gengrong Liu, 2020 (18)

M. Del, 2020 (19)

H. Murata, 2020 (20)

H. Murata, 2020 (20)

\section{Age Clinical presentation}

49 y Pelvic pain, vaginal discharge and bleeding

48 y Abnormal vaginal bleeding, fixed mass in the left inguinal area measuring $8 \times 8 \mathrm{cr}$ $74 \mathrm{y}$ Fever, night sweats, and a weight loss of $4 \mathrm{~kg}$ in the past year

36 y Vaginal bleeding, pelvic pain, dysuria and asthenia without fever

50 y Asymptomatic, bulky cervix in examination

46 y Abnormal genital bleeding
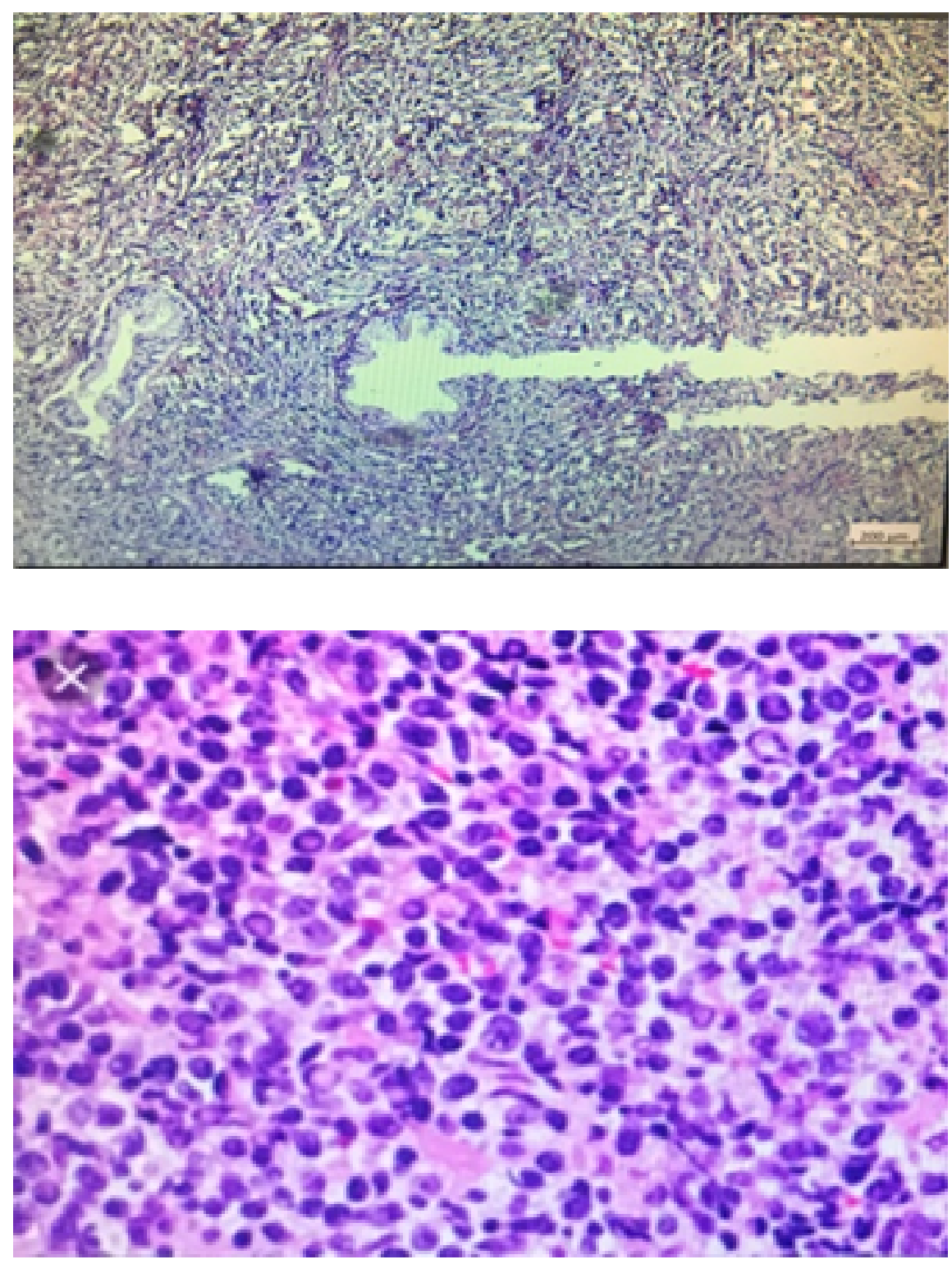


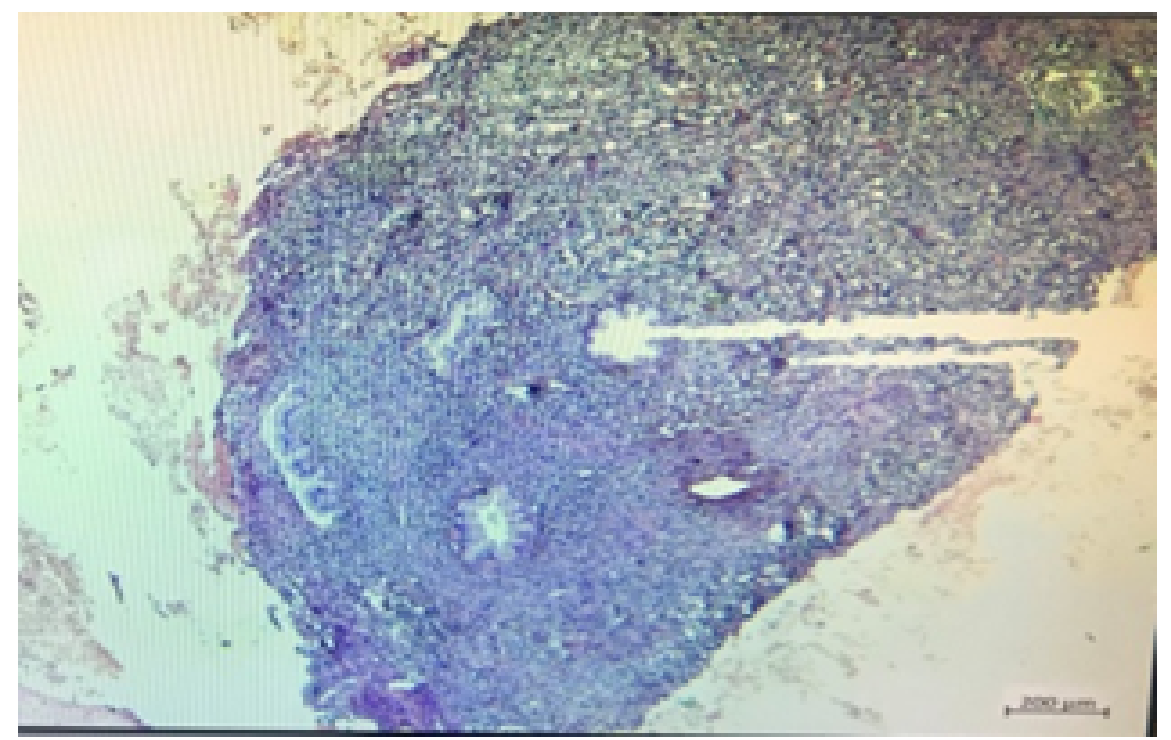

Fig 1. Diffuse infiltration of the ectocervical and endocervical stroma by the monomorphic population of malignant lymphoid cells. The cells had intermediate to large, round to ovoid and irregular nuclei surrounded by scanty neoplasm. The Neutrophilic infiltration and large foci of necrosis were also noted.

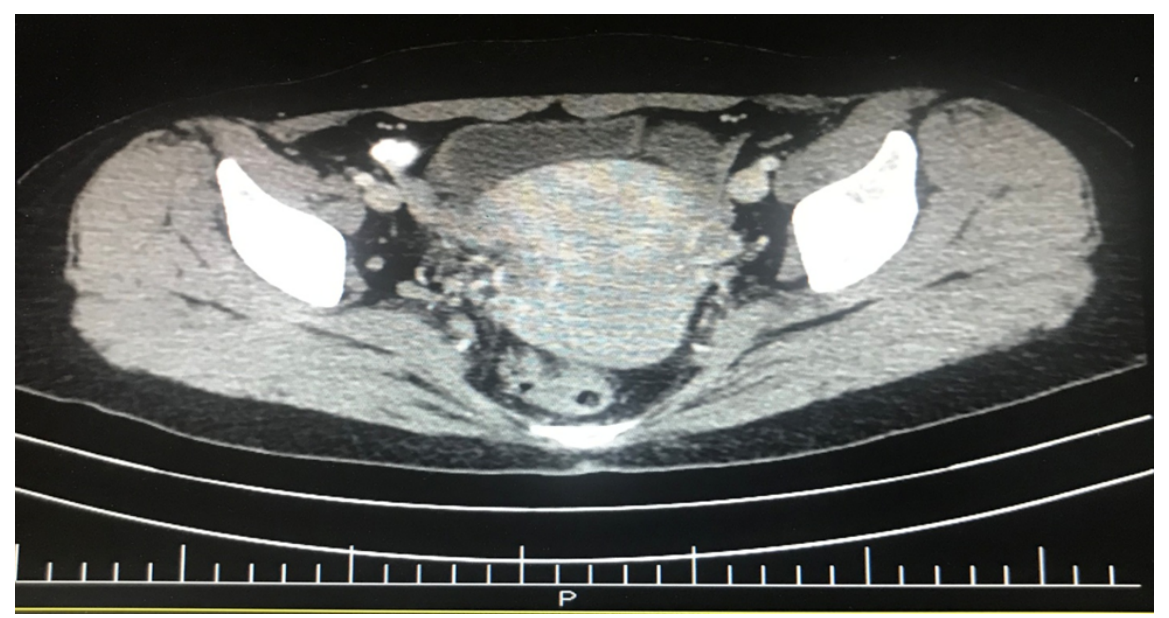

Fig 2: Axial section of CT scan showing the increase in size of the cervix with no cervical mass. 

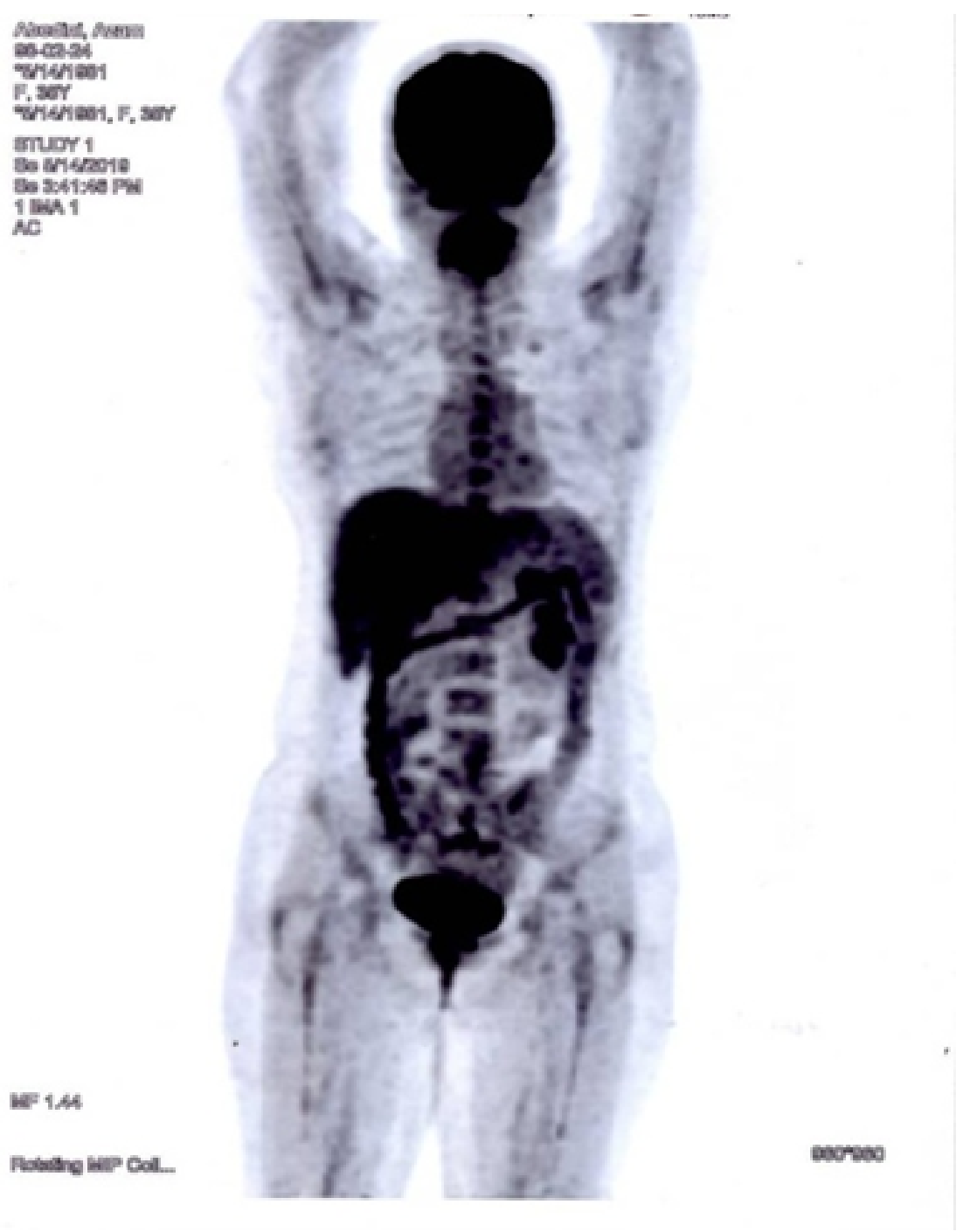


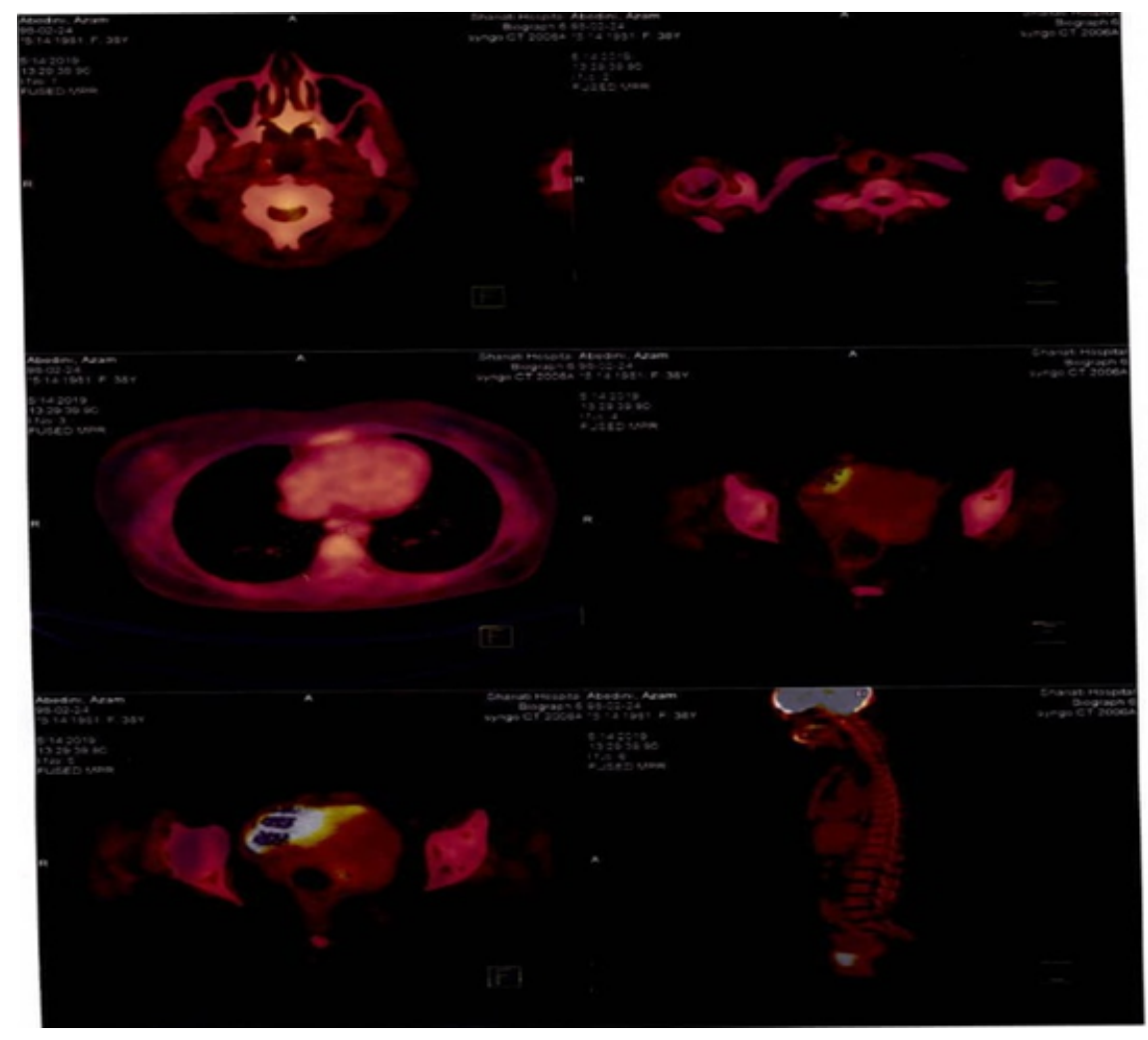

Fig 3: PET scan after eight cycles of chemotherapy showing almost complete regression of the cervical mass and its extensions. 


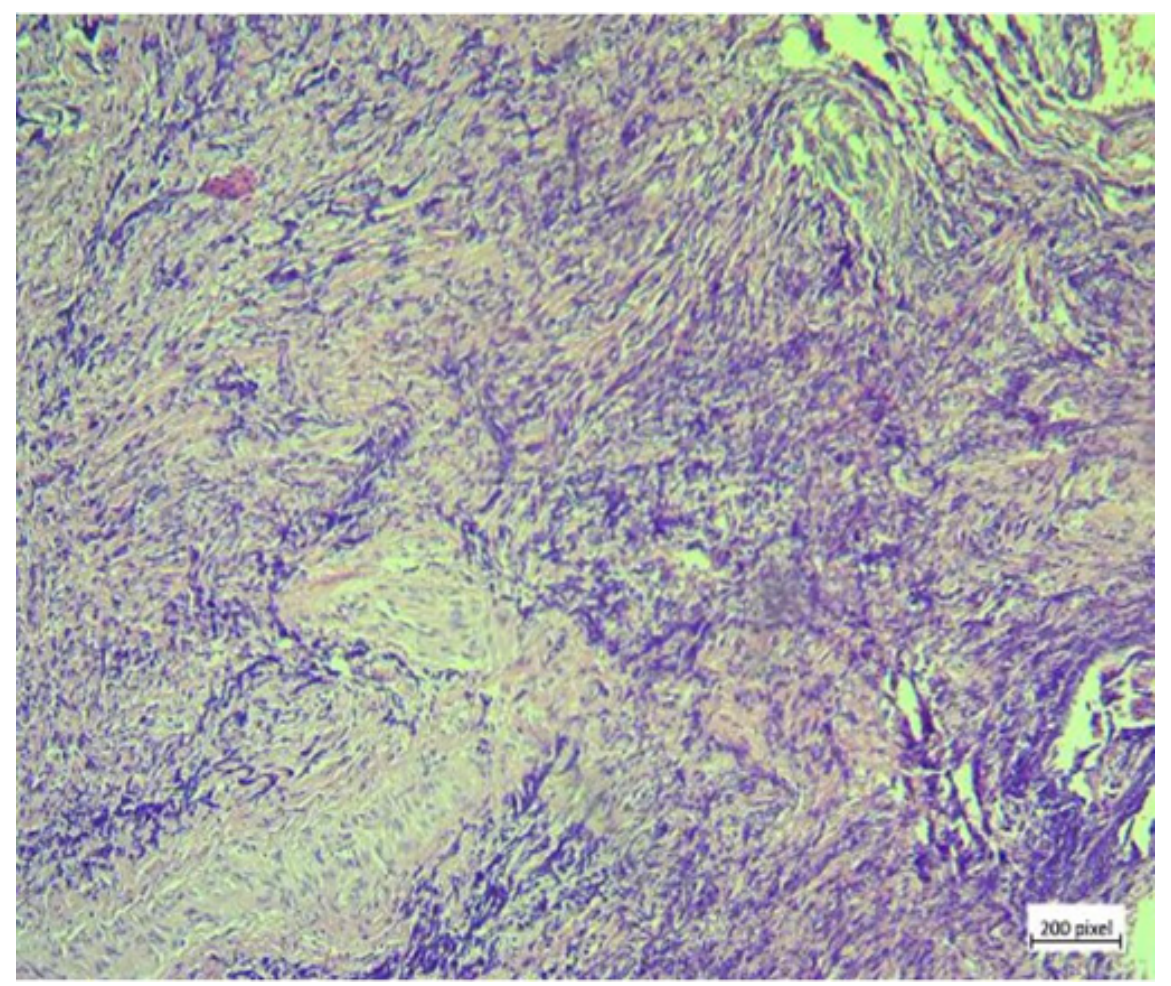




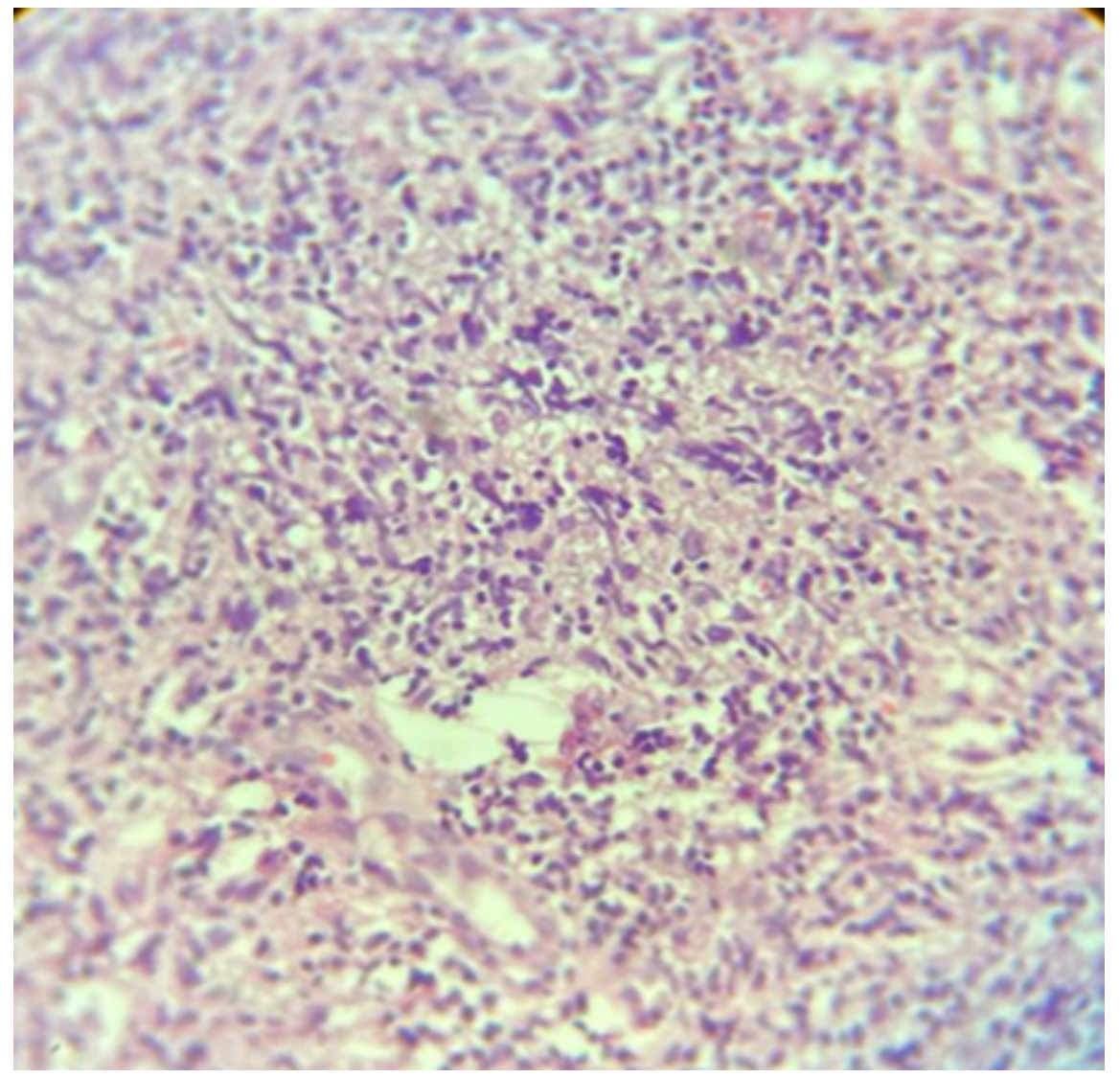

Fig. 4: A . Photomicrograph showing tumor cells infiltrate stroma without destroying glandular or squamous epithelium. B . Round, loosely arranged neoplastic cells with scanty cytoplasm. Neutrophilic infiltration was also noted. 


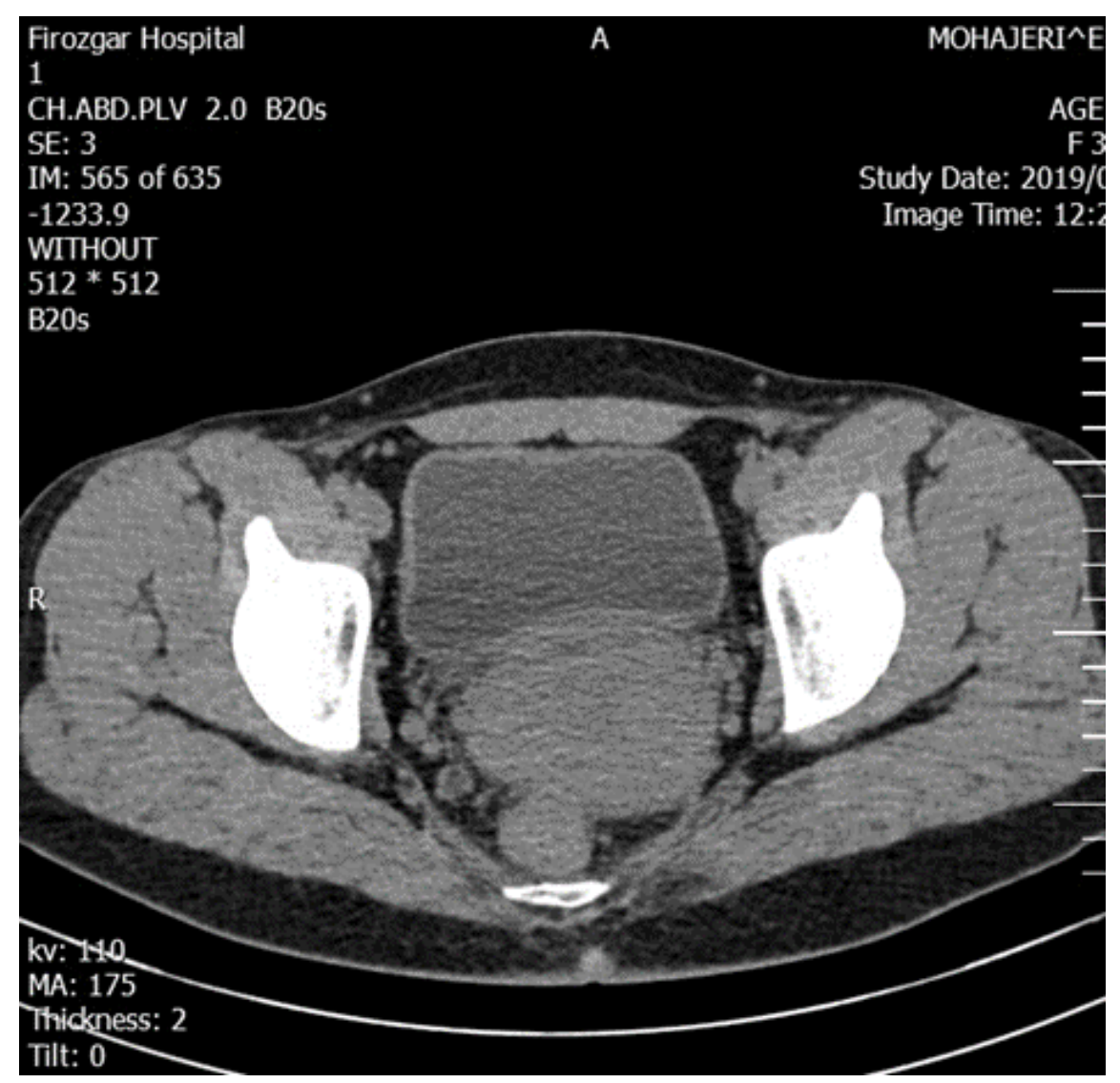




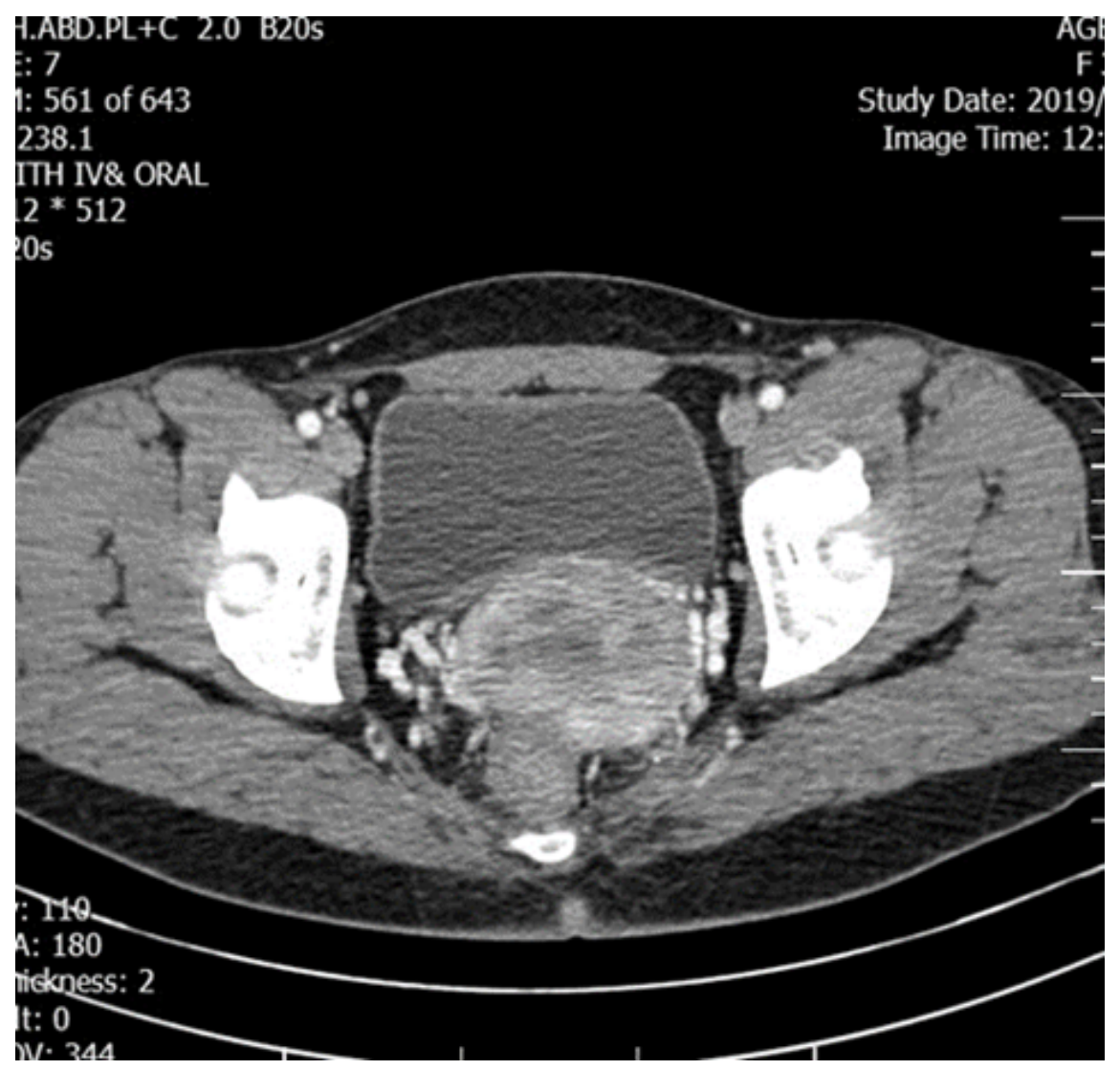

Fig. 5: Axial section of computed tomography showing a $63^{*} 74 \mathrm{~mm}$ hypodense solid mass in cervix with heterogeneous enhancement.

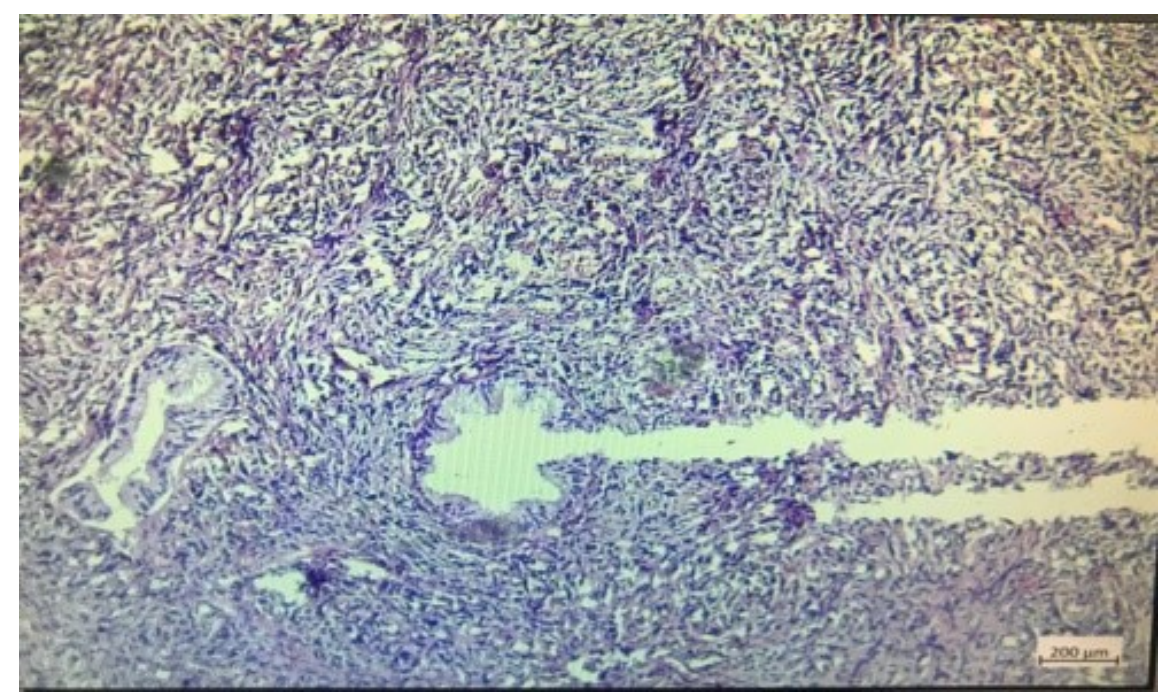



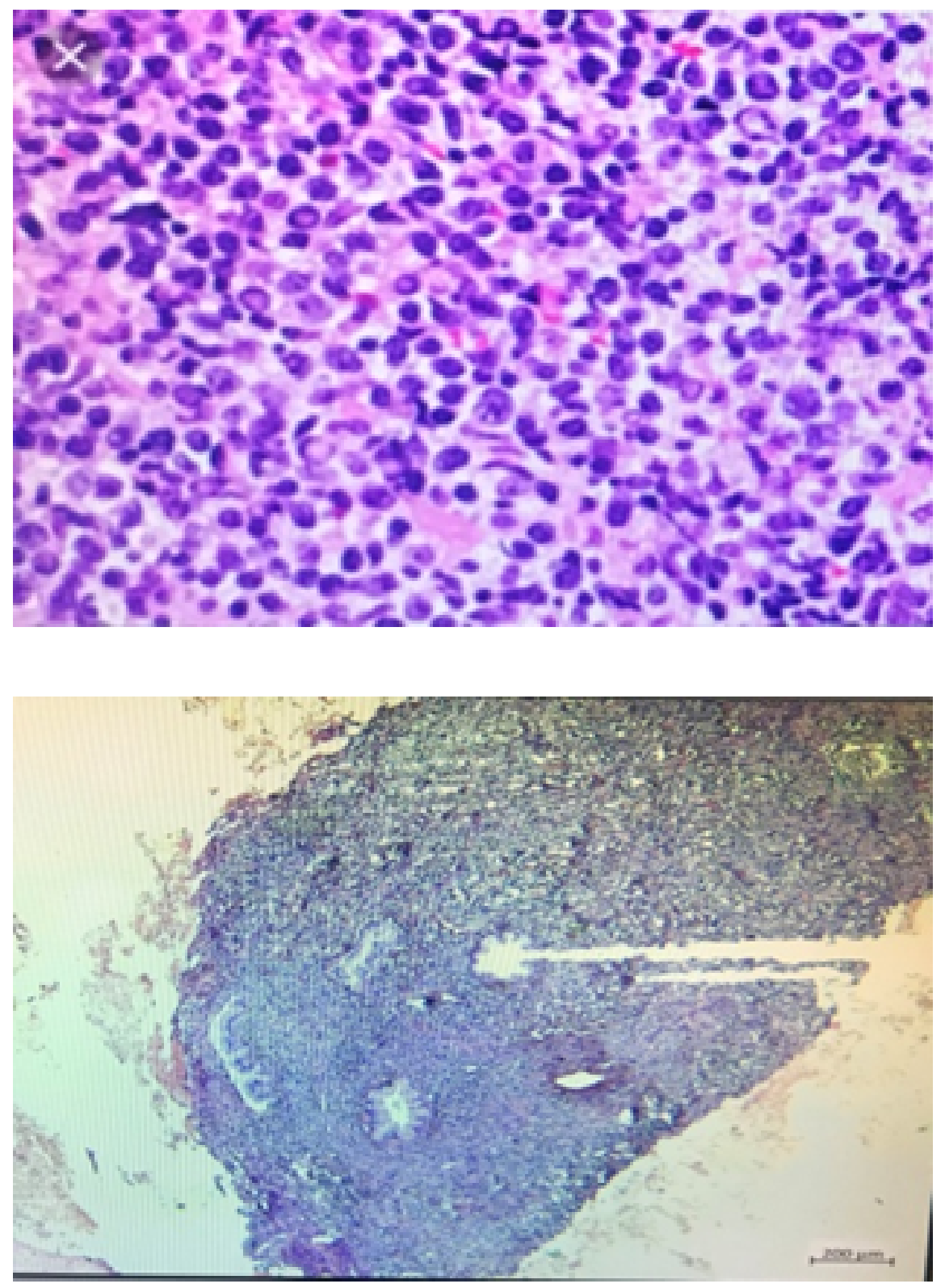


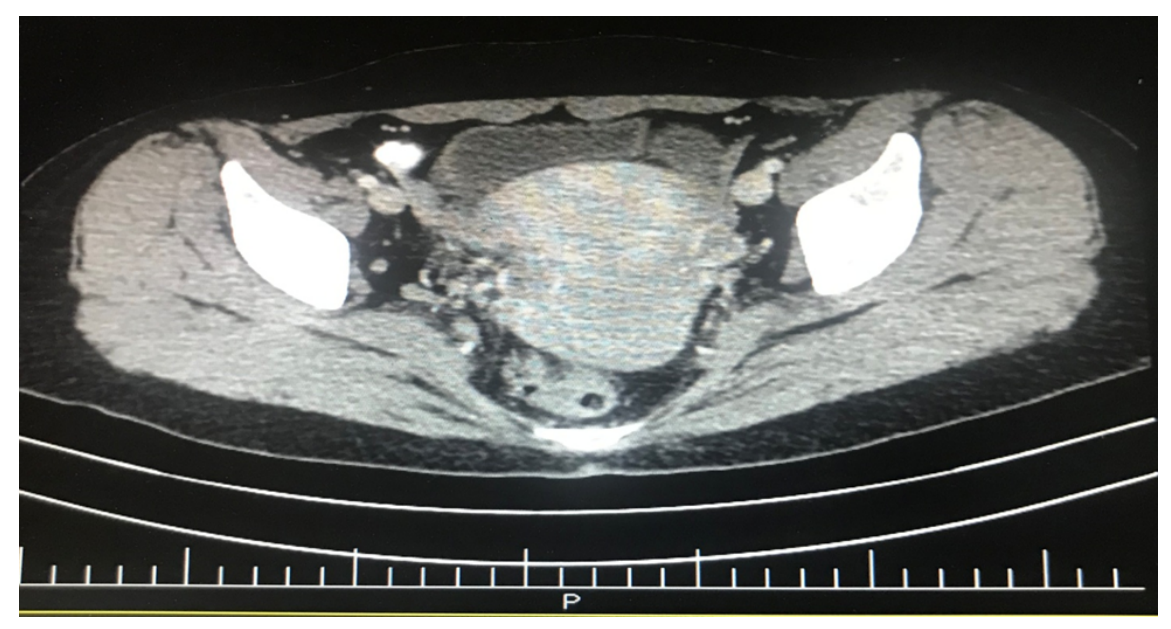

Dirad Awe acest

F, sor

"ristant, F, sor

smur 1

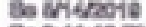

se 3:61:6e PN

1 เім 1

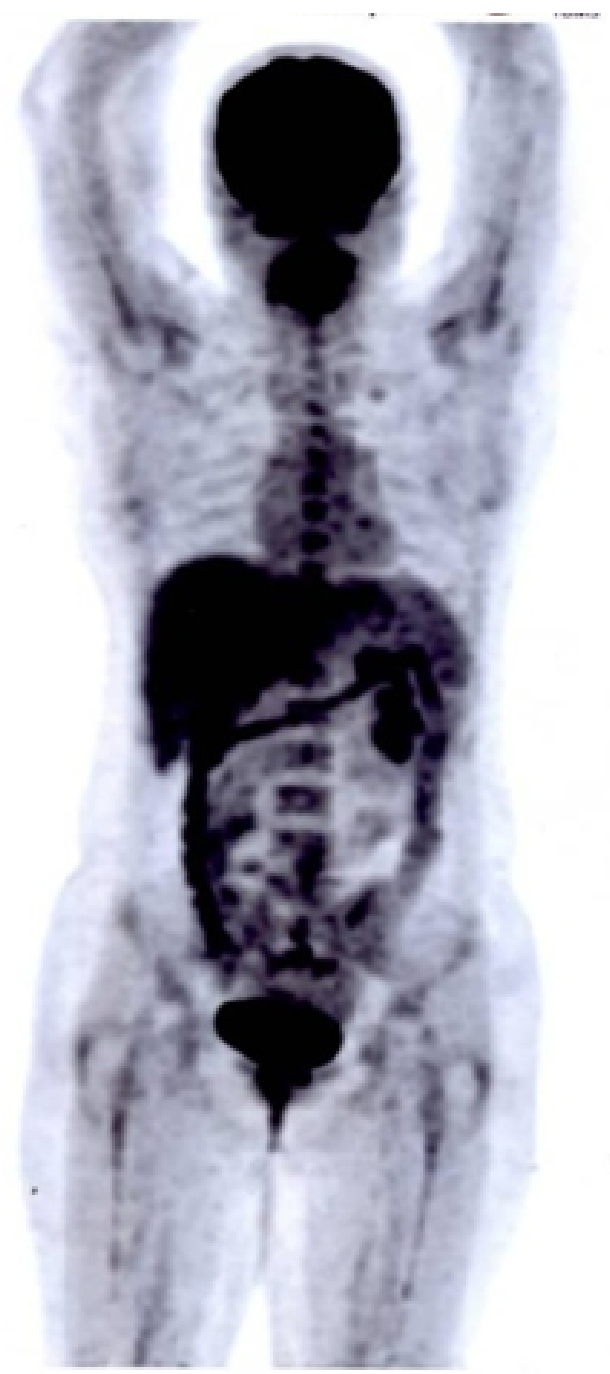

nocreso 

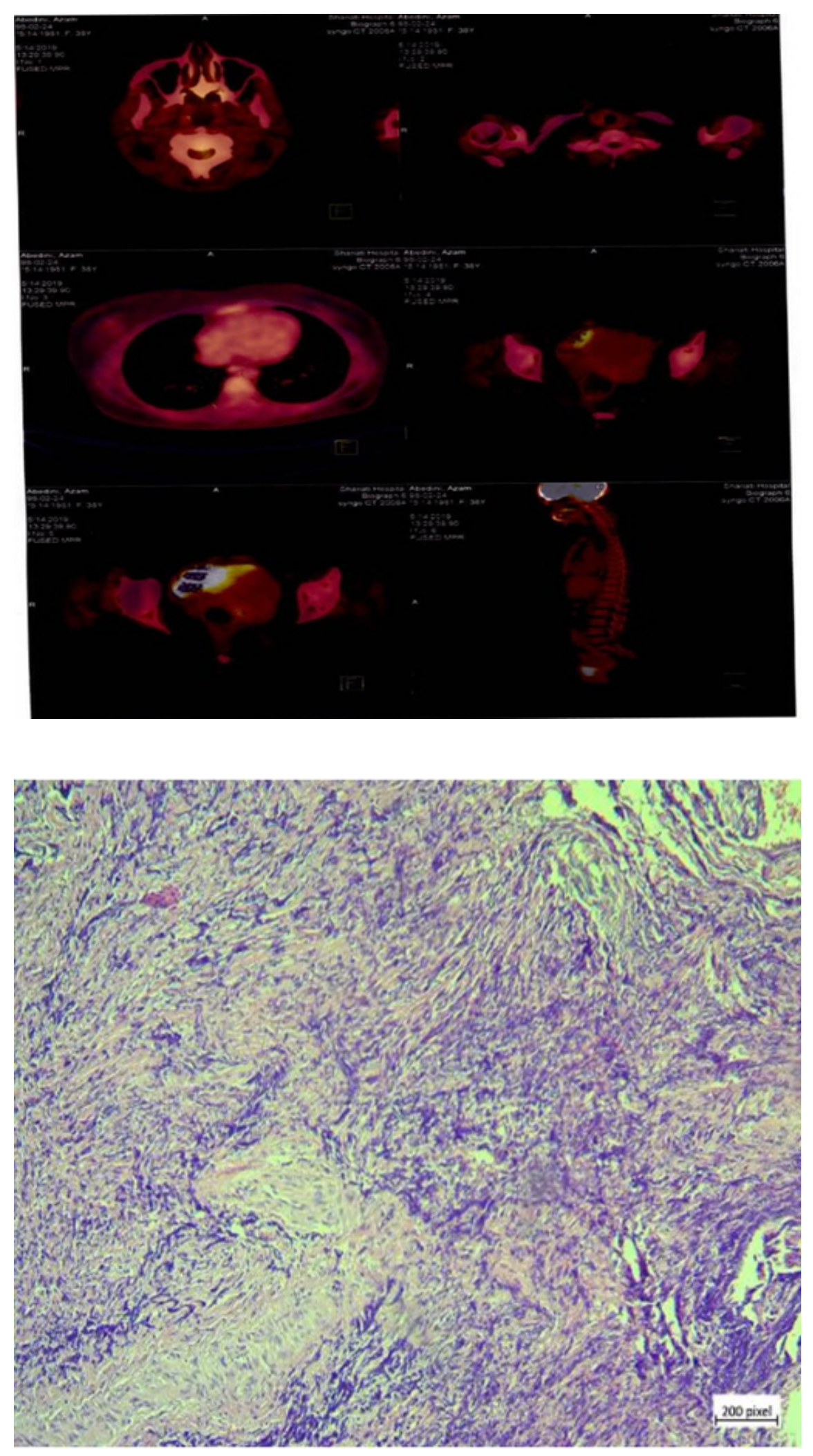


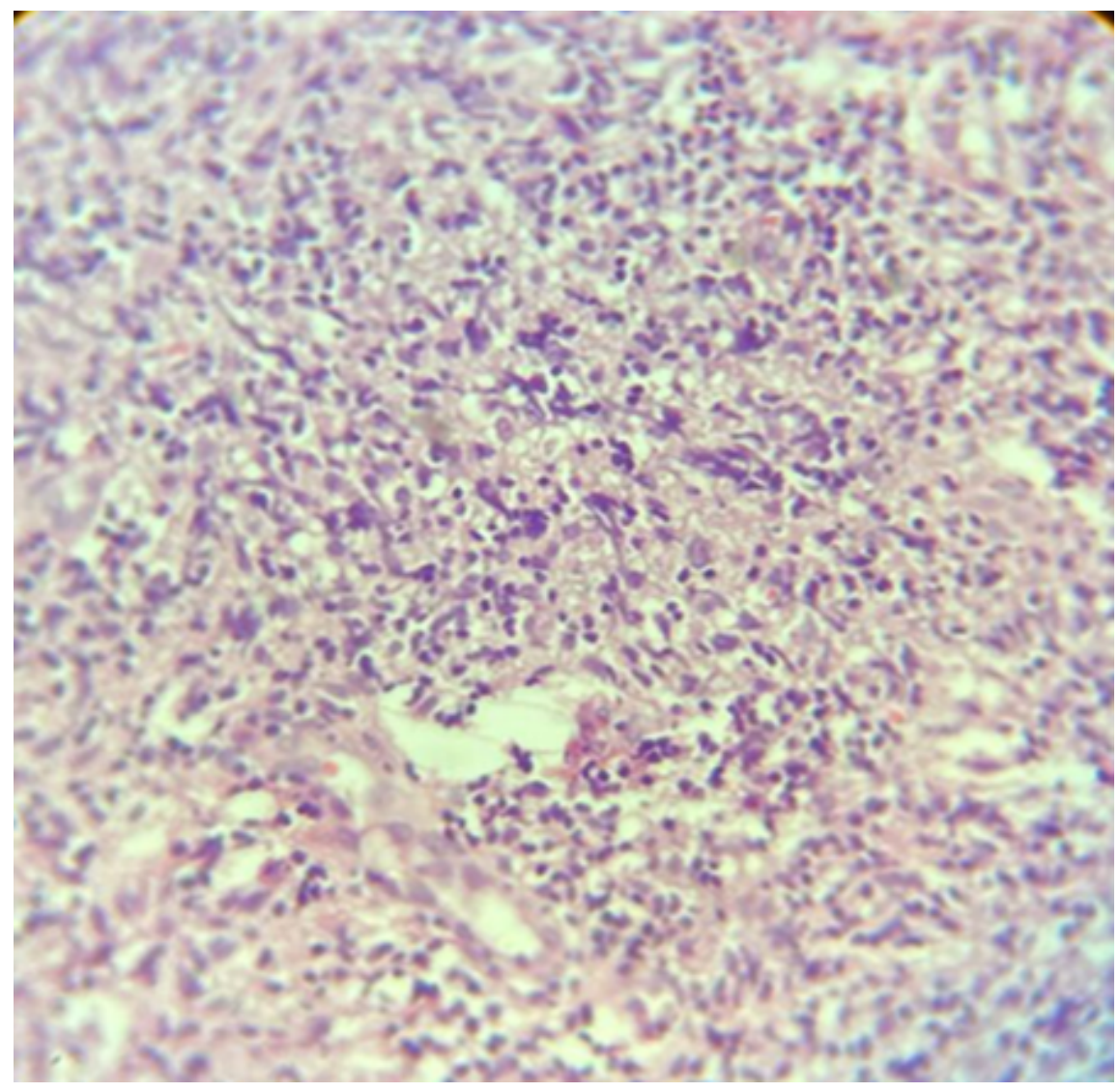




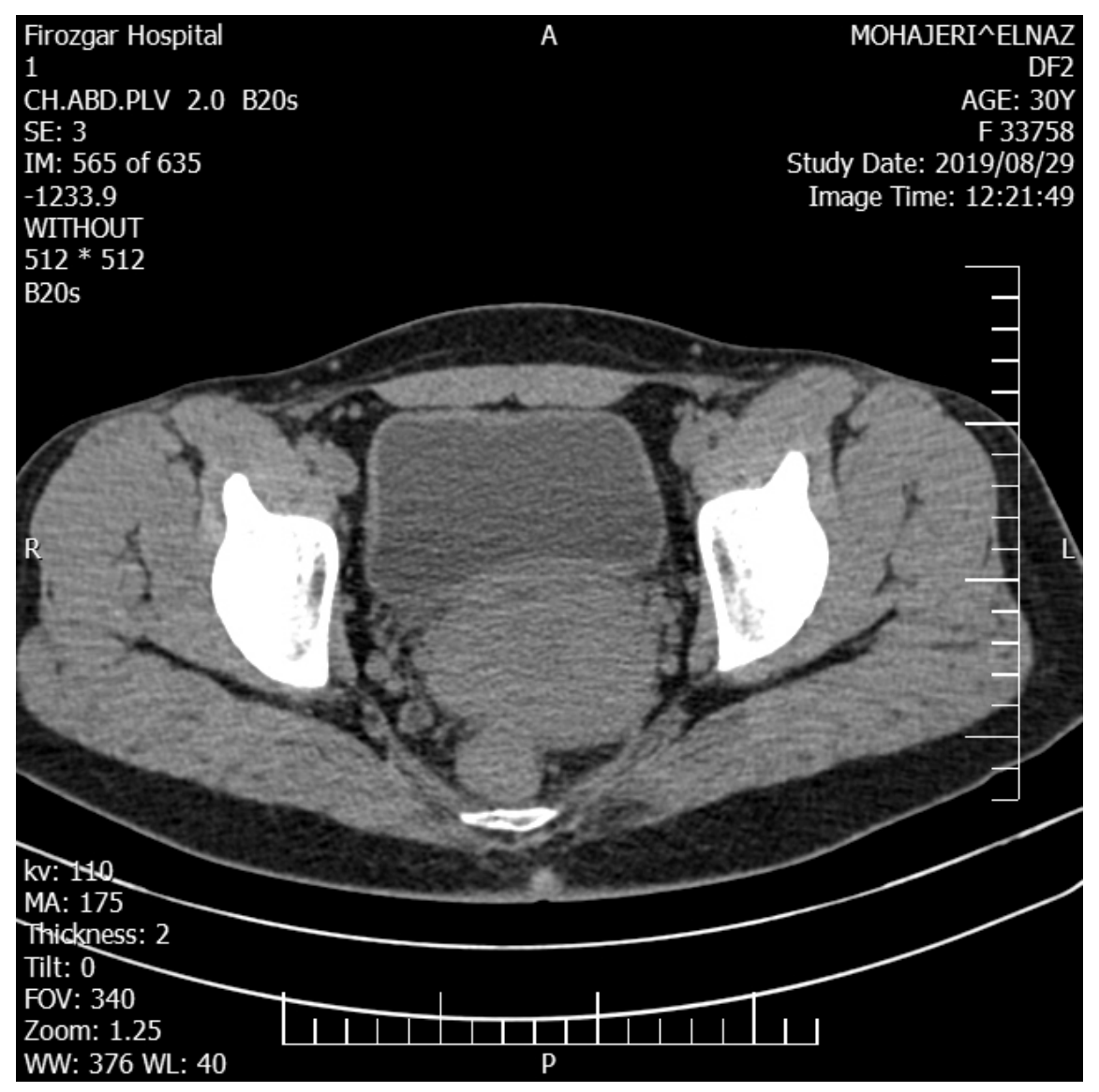




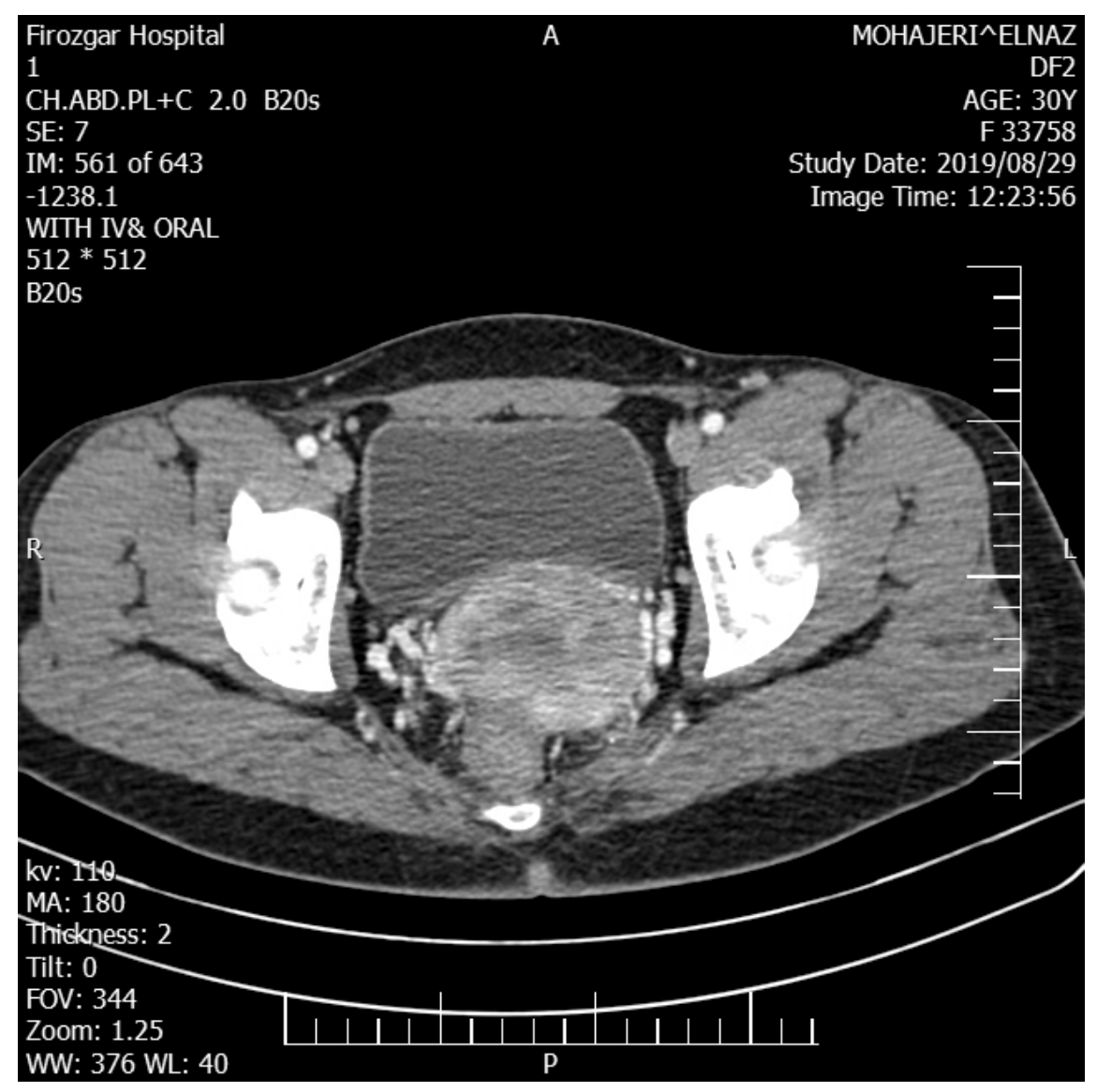

